\title{
O que dizem os alunos sobre os conflitos decorrentes de sua relação com os professores
}

\author{
Ernesto Barros André ${ }^{1}$ \\ ORCID: 0000-0002-6948-212X
}

\section{Resumo}

0 presente artigo apresenta resultados de uma pesquisa sobre os conflitos decorrentes da relação professor-aluno, vistos na ótica dos discentes. A mesma foi realizada numa escola secundária de Angola. Nele se pretendeu escrutinar as causas e os tipos de situações resultantes do relacionamento em sala de aula entre o docente e o discente. Na prossecução dos objetivos, aplicou-se a metodologia qualitativa. Foram realizadas entrevistas grupais semiestruturadas com a participação de 129 alunos, cujos dados foram analisados através do método de análise de conteúdo com a aplicação do software maxqda versão 12 . Os resultados foram organizados em torno de três temas: concepção de conflitos por parte dos alunos, situações conducentes aos conflitos e/ou situações de conflitos, e tipos de conflitos. $\mathrm{Na}$ perspectiva dos alunos daquela escola, a pesquisa demonstrou que os conflitos mais relevantes da relação professor-aluno relacionam-se com o desrespeito das normas éticodeontológicas por parte dos docentes e de manifestação de atitudes e comportamentos indecorosos tanto da parte dos alunos como da parte dos professores consubstanciados no assédio sexual, no suborno e tantos outros, provocando, desta feita, agressões verbais e físicas, vingança, rancor e ódio assim como outros tipos de males que "envenenam" a relação professor-aluno. Sendo um estudo de caso ocorrido num estabelecimento escolar do ensino público, trabalhos semelhantes deverão enfocar em mais centros com o objetivo único de aferir ou comparar os resultados com vistas à sua generalização nessa região.

\section{Palavras-chave}

Conflitos - Relação professor-aluno - Angola.

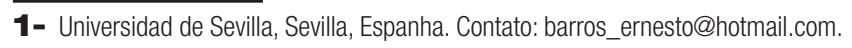




\section{What students say about the conflicts arising from their relationship with teachers}

\section{Abstract}

This article presents the results of a research on the conflicts arising from the teacherstudent relationship, seen from the students' perspective. It was conducted at a secondary school in Angola. It aimed to scrutinize the causes and types of situations resulting from the classroom relationship between the teacher and the students. In pursuit of the objectives, the qualitative methodology was applied. Semi-structured group interviews were carried out with the participation of 129 students, whose data were analyzed through a content analysis method using Maxqda software, version 12. The results were organized around three themes: conception of conflicts by the students, situations leading to conflicts and / or conflict situations, and types of conflicts. From the perspective of the students from that school, the study revealed that the most relevant conflicts of the teacher-student relationship are related to disrespect of the ethical-deontological norms by teachers and the manifestation of unseemly attitudes and behaviors on the part of both students and the teachers embodied in sexual harassment, bribery and so many other issues, thus provoking verbal and physical aggression, revenge, resentment and hatred as well as other types of evils that "poison" the teacher-student relationship. Since the case study occurred in a public education school, further research should focus on more schools with the sole objective of measuring or comparing the results in order to generalize it in that region.

\section{Keywords}

Conflicts - Teacher-student relationship - Angola.

\section{Introdução}

No pensamento de alguns autores (HAMRE; PIANTA, 2001; MYERS; PIANTA, 2008), o bom relacionamento entre o aluno e o professor influi sobre o desenvolvimento dos conhecimentos e sobre o funcionamento emocional dos alunos. Por isso, o melhor desempenho escolar e melhores níveis sociais dependem de um relacionamento de alta qualidade (BERRY; O'CONNOR, 2010; MALDONADO-CARREÑO; VOTRUBA-DRZAL, 2011; PIANTA; STUHLMAN, 2004). Daí as diferentes teorias sobre a importância do relacionamento entre alunos e professores ou entre criança e o adulto para o seu desenvolvimento, como sublinham Terri J. Sabol e Robert C. Pianta (2012).

Tal como constatado em diversas investigações, o relacionamento positivo com os docentes pode facilitar a adaptação dos alunos em novas realidades, contribuindo, desta feita, na aprendizagem de habilidades essenciais para a trajetória escolar e para a redução dos problemas de comportamentos violentos, dando acesso aos conflitos de variadas índoles, conforme explicam Erin E. O'Connor, Brian A. Collins e Lauren Supplee 
(2012) e Rebecca B. Silver, Jeffrey R. Measelle, Jeffrey M. Armstrong e Marilyn J. Essex (2005). Também, no decorrer dos tempos, as interações tanto positivas como negativas dos professores podem influir em todo percurso escolar, profissional e social deste aluno com uma incidência na produção de conflitos (CROSNOE; JOHNSON; ELDER, 2004; HAMRE; PIANTA, 2006; PIANTA; ALLEN, 2008). Claudivan Sanches Lopes (2001) defende que a relação professor-aluno deve ser assimétrica, sendo essa interação de duas componentes, isto é, de apoio/suporte, tal como a intimidade, e de componente de estresse, tal como o conflito (HAMRE et al., 2008).

Com base nesses aspectos, vários estudos tiveram lugar, e em vários países, no intuito de medir o impacto da qualidade do relacionamento professor-aluno em discentes de diferentes idades, como nos Estados Unidos (BERRY; O'CONNOR, 2010, 0'CONNOR, COLLINS; SUPPLEE, 2012; WEBB; NEUHART-PRITCHETT, 2011), na Holanda (KOOMEN et al., 2012), na Noruega (DRUGLI; HJEMDAL, 2013) e outros.

Ainda, a respeito dos conflitos escolares, muitos trabalhos foram conduzidos relacionados à violência e ao bullying nas escolas (HOJBOTA et al., 2014), à indisciplina na sala de aula (AMADO et al., 2014), aos conflitos de origem multicultural (PATIÑOSANTOS, 2016; VIEIRA, 2016), aos conflitos escolares em países com guerra civil ou outras formas de violência (BHUTTA; YOUSAFZAI; ZIPURSKY, 2010; HAREL-FISCH et al., 2010; TOROS, 2013), às causas e efeitos do conflito nas escolas (SALLEH; ADULPAKDEE, 2012; OMISORE; ABIODUN, 2014; OZGAN, 2016), ao impacto causado nos professores (GÖKSOY; ARGON, 2016; VASQUEZ-SALGAD0; GREENFIELD; BURGOS-CIENFUEGOS, 2015), às estratégias para lidar com a violência nas escolas (BOURNE et al., 2015), à resolução e mediação dos conflitos escolares (ABDULKADIROGLU; CHE; YASUDA, 2011; DE GUZMAN; AMADOR MUÑOZ; VARGAS VERGARA, 2011; DOGAN, 2016; DOUCEY, 2011; SALLEH; ADULPAKDEE, 2012; SHAHMOHAMMADI, 2014; TATLAH; IQBAL, 2011; THAKORE, 2013; WHITESIDE, 2016).

Alguns trabalhos realizados no contexto africano são dignos de realce quanto à gestão dos conflitos pela semelhança do contexto. Isto é, em Gana, um estudo foi levado a cabo sobre a gestão de conflitos nas escolas baseando-se no papel da liderança, cujos resultados apontam para a construção de consensos entre o staff dirigente e os estudantes (AFFUL-BRONI, 2012), enquanto no Kenya, Janet Wagude (2015) constatou a influência da idade dos diretores nos estilos de gestão de conflitos, no qual, até os 45 anos, os diretores aplicam o evitamento e, entre 46 e 56 anos, o compromisso.

Também, foi desenvolvido um trabalho sobre o bullying e a relação professor-aluno na perspectiva dos alunos, cujos resultados revelam que os agressores e as suas vítimas manifestam relações negativas com os professores (LAMAS; FREITAS; BARBOSA, 2013). Todos os trabalhos referenciados acima foram vistos na conjuntura geral da comunidade escolar. Aqui particularizamos as percepções daquele que, dentro da relação conflituosa, sofre as consequências não só do conflito, mas também da posição de inferioridade: o aluno, que através dos seus depoimentos falou alto sem silenciar a subjetividade.

Apesar de se tratar de estudos relevantes na psicologia, na sociologia e na educação, investigações como estas são quase inexistentes em Angola, assim como os instrumentos de medição da qualidade do relacionamento professor-aluno na esfera científica deste país. 
0 contexto educacional angolano caracteriza-se pelas mudanças operadas no sistema político logo após sua independência, em 1975, com a implantação de princípios do marxismo-leninismo, quando foi produzida a primeira reforma educativa e, em 1992, pela passagem do sistema monopartidário para o multipartidarismo. Em 2001 nasce a terceira reforma do sistema educativo, baseada na Lei de Bases do Sistema Educativo Lei $n^{\circ}$ 13/01, de 31 de Dezembro (ANGOLA, 2001), cuja avaliação, em 2011, resultou na criação de uma nova Lei de Bases do Sistema da Educação e Ensino - Lei nº 17/16, de 7 de Outubro (ANGOLA, 2016) que, por sua vez, organiza a educação em três níveis, a saber: o primário, secundário e o superior, e define no seu segundo capítulo os princípios gerais que regem o sistema de educação e ensino. No artigo $15^{\circ}$ retrata a promoção dos valores morais, cívicos e patrióticos para a preservação da soberania nacional, da paz e do Estado democrático de direito.

A cultura da paz proporciona o evitamento ou a manutenção de um nível mínimo de conflito para o desenvolvimento harmonioso da sociedade, pela restauração de um clima de confiança entre os membros da comunidade, caracterizada pela promoção dos níveis de conhecimento e de cuidados socioemocionais.

0 propósito deste artigo é de contribuir com um levantamento criterioso, desde o ponto de vista do aluno sobre as concepções, situações e tipos de conflitos decorrentes do relacionamento professor-aluno numa escola do contexto angolano, o que propicia melhores conhecimentos sobre as situações de conflitos reinantes naquela escola assim como os tipos mais frequentes, condicionando outros estudos para prevenção e resolução eficaz dessas situações na base das propostas dos intervenientes.

\section{Método}

A presente pesquisa, desenvolvida numa escola do ensino secundário da Província angolana de Cabinda, que passou por vicissitudes de uma guerra com mais de 40 anos, e cujos pais e avós de muitos dos estudantes foram militares, tem como finalidade apresentar uma realidade resumida de uma situação educacional relativa à percepção da problemática de conflitos entre docentes e alunos. Inscreve-se para escrutinar um problema constatado a esse nível com o intuito de caracterizá-lo a partir da concepção, das causas e o tipo de situações produzidas numa perspectiva de procurar vias para minimizá-las. Não sendo abrangente para todas as escolas do I Ciclo do Ensino Secundário da Região, abraçamos o estudo de uma única escola, neste caso específico, para aprofundar o conhecimento sobre ele e oferecer subsídios para as novas pesquisas sobre o caso, o que Robert K. Yin (2001), denomina estudo do caso.

\section{Objetivo e questões de investigação}

0 objetivo principal da nossa investigação prende-se com a análise dos conflitos decorrentes da relação professor-aluno, na visão dos alunos do Ensino Secundário do I Ciclo da Escola do Ensino Secundário no 154/BZ de Buco-Zau na Província angolana de Cabinda que é uma Instituição Pública, criada à luz do Decreto-Executivo no 21/02, de 02 de Dezembro, publicado em Diário da República n 20, I Série, de 14 de Março 
de 2003, saído do Gabinete do Ministério da Educação. Concentramos a nossa atenção especialmente em três questões de investigação:

- Qual é a concepção dos alunos sobre os conflitos? do aluno?

- Que situações são identificadas como conducentes e/ou de conflitos na perspectiva

- Quais são os tipos de conflitos que decorrem do relacionamento entre professoraluno de ponto de vista do discente?

\section{Participantes}

A nossa amostra se constitui num grupo de 129 alunos com idades compreendidas entre 16 e 22 anos, selecionados através do preenchimento de um questionário para identificação daqueles que já tiveram atritos com os docentes e a sua disponibilidade em nos prestar os seus depoimentos relativos a esses conflitos. Devemos aqui realçar que não foi fácil obter essa amostra, dadas as dificuldades que a comunidade enfrenta em prestar declarações a pessoas não pertencentes a ela, por causa das veleidades do estigma que a guerra civil deixou. 0 número reduzido dos constituintes da amostra indica exatamente isso. Todavia, essa amostra intencional foi reagrupada ao acaso e segundo a disponibilidade no horário letivo, em 15 subgrupos de 7 elementos e 3 subgrupos de 8 elementos com a participação de apenas 7 meninas.

\section{Instrumentos de recolha de dados}

Nessa investigação caracterizada de qualitativa, com a realização das entrevistas grupais semiestruturadas, os seus guiãos foram submetidos a uma apreciação e aprovação dos especialistas das áreas de pedagogia, sociologia e psicologia. Na base da situação a analisar, o questionário para além de outras, promoveu perguntas essenciais, a saber: Como os alunos concebem o termo conflito? Quais são os comportamentos e atitudes dos docentes que levam aos conflitos na visão dos alunos? Quais as situações de embaraço que possam conduzir aos conflitos entre professores e alunos? Que situações reais e os tipos de conflitos são produzidos na relação professor-aluno?

A realização das entrevistas nos grupos constituídos, cujo mestre de cerimônia foi o promotor do projeto, com a presença dos 7 ou 8 elementos do subgrupo, consistiu em apresentar as perguntas semiestruturadas ao grupo, esclarecendo que as respostas estavam sendo gravadas através de um microgravador, no fim do qual iniciou-se a transcrição das entrevistas que deu lugar à análise de dados. Cada subgrupo levou em média 4 horas de tempo na execução dessa tarefa.

\section{Análise de dados}

Os dados recolhidos através das entrevistas foram analisados na perspectiva de obtenção da informação precisa e na análise estrutural foi utilizado o sistema de categorias e códigos como proposto por Matthew B. Miles e Michael A. Humberman (1994) e assistido 
pelo programa MAXQDA, versão 12. Os segmentos codificados extraídos na Maxqda resumem a essência do trabalho cujos conteúdos essenciais codificados estão agrupados em 3 categorias, a saber:

- Informação geral sobre as situações conflituais;

- Conflitos da relação professor-aluno: atritos ressentidos ou vividos por parte dos alunos na sua relação com o docente;

- Os diferentes tipos de conflitos da relação professor-aluno.

\section{Resultados}

$\mathrm{Na}$ base da investigação levada a cabo, situamos os resultados em três eixos consubstanciados pelas perguntas principais colocadas, as quais se articulam com a apreensão da concepção do conflito pelos alunos, às causas e às situações de conflitos assim como ao tipo de situações conflituosas vividas naquela unidade escolar.

\section{Concepção particular do conflito pelos alunos ${ }^{2}$}

$\mathrm{Na}$ idealização dos alunos, o conflito sempre foi "uma coisa ruim" e considerada como tal entre as partes envolventes na investigação, por isso que os alunos apontam como sendo uma situação contraditória, cuja origem é uma das pessoas implicadas. Repentinamente, sem qualquer contradição, o surgimento do conflito é inexplicável. Os alunos apontam ainda a existência de um desacordo ou a não-aceitação da opinião de outrem como sendo a base principal em que se assenta o conflito, sustentando a incompreensão, a discussão ressentida negativamente.

Aluno 19: Conflito é problema que alguém pode ter com um outro indivíduo; uma situação em que não há compreensão entre as pessoas.

Essas situações à revelia, provocando desentendimento, segundo o pensar dos alunos, não ficam isentas de consequências nefastas para a convivência humana ou nas relações interpessoais.

Aluno 18: Como já acabou de dizer o colega, o conflito é algo causado por duas pessoas ou mais de duas pessoas e se não for resolvido o mesmo pode dar várias consequências.

A visão acima exposta não coaduna com a atual, dado que as situações conflituais dinamizam o pensamento, operam mudanças significativas no modo de apreender a realidade, o que leva ao desenvolvimento das sociedades, tendo em conta como são apresentados os diferentes pontos de vista. Por isso, na resolução do conflito faz-se a escolha mais eficaz.

2- Os alunos foram identificados por numeração de 1 a 129, e serão assim nomeados no texto. 
Os alunos admitem a existência de conflitos consigo próprio, ou seja, conflito intrapessoal com a natureza própria do homem, sendo o homem um ser pensante. A par do surgimento do conflito intrínseco, pode haver um surgimento extrínseco, no seio da comunidade, ou na sociedade em geral, ou, ainda, entre duas pessoas.

Aluno 3: Conflito para mim é o desentendimento que pode surgir no meio deste ou daquele.

A interação social no meio ambiente como forma de comunicação, é produtora de situações contraditórias donde podem resultar os conflitos. Neste posicionamento, o conflito aparece como reação a um estímulo na comunicação deficiente entre indivíduos colocados no mesmo meio ambiente. Para tal, é uma maneira de buscar respostas a certas situações prevalecentes no agrupamento social. Aqui aparece o meio ambiente como fonte que alimenta as contradições conducentes aos conflitos.

Aluno 12: A interação, a interação social é a relação de comunicação entre indivíduos. Então o conflito faz parte do meio. Para que nós sejamos amigos, deve existir o conflito. É uma relação de interação entre eu e outro indivíduo e não só. Esse conflito também faz bem no nosso seio porque através do qual nós vamos buscar as respostas, porventura se existe algo errado nesse conflito nós vamos ser corrigidos praticamente porque o termo conflito é uma forma de interação, é uma forma de interação. Interação, temos interação social e interação... Quando se trata de interação, interação é uma forma de comunicação. Agora, interação social é o resultado de um ou mais indivíduos na comunicação. Conflito é uma relação de interação.

Neste grupo alvo, ainda, entende-se por conflito o desentendimento entre duas pessoas, de acordo com a sua personalidade, fruto de comportamentos e hábitos adquiridos ao longo do tempo, formando, desta feita, o carácter do homem.

Assim, os alunos reconhecem que o conflito nasce de uma divergência de ideias ou de pensamentos entre pessoas. E se as partes puderem conciliar positivamente as suas divergências, isto pode produzir melhorias no relacionamento entre si.

Analisado neste campo, inclinamo-nos a perceber as situações que levam aos conflitos naquele ambiente, tal como exposto pelos participantes deste projeto.

\section{Situações conducentes e/ou situações de conflitos}

As situações identificadas pelos alunos e manifestadas pelos professores através das suas atitudes e comportamentos são, na sua maioria, de ordem ético-deontológica por parte do professor e de ordem disciplinar e comportamental por parte dos alunos. Identificadas como situações conducentes aos conflitos, de igual forma as mesmas situações debeladas provocaram conflitos tal como relatado pelos alunos entrevistados no centro escolar em análise.

Tendo em conta o pronunciamento dos nossos entrevistados, e no espírito de tipicidade, organizamos em quatro grandes grupos as situações que se consubstanciam com o abuso da autoridade professoral, o desrespeito das normas, as medidas disciplinares excessivas, as questões comportamentais e atitudinais dos professores e alunos. 
No primeiro grupo encontramos tanto situações afetivas, como, por exemplo, o namoro, quanto situações relacionais impertinentes, como é o caso do assédio sexual, da pedofilia, da rivalidade com os alunos, do desacordo a respeito das intenções assediantes dos professores que a maioria das alunas tem sofrido. 0 conflito aqui é ditado pela posição de superioridade e inferioridade entre o docente e as discentes ou então entre o predador e a presa, às vezes para troca de notas (neste caso com consentimento), ou forçosamente com todas as consequências possíveis. Na maioria dos casos a vítima resigna-se por vergonha de não denunciar essas práticas e, em certos casos, as meninas fincam o pé para não se deixar seduzir pelas propostas do professor tentador. Desta maneira, as partes acabam por entrar em situações de desavenças como no caso do seguinte relato:

Aluno 2: [...] quando o professor pretender uma menina dentro da sala e essa por sua vez se negar, o professor fica a quedar a aluna na sua disciplina mesmo quando esta estiver a tirar boas notas. [...] Este por sua vez, quando se aperceber vai querer atribuir a falta de respeito à aluna porquanto a aluna tem a sua razão.

Neste primeiro grupo, denominado abuso da autoridade professoral, ainda nos relatos dos alunos podemos constatar a não consideração do trabalho do aluno, o complexo de superioridade manifestado por certos professores, o não respeito do horário escolar, a descontextualização dos problemas e os trabalhos caseiros infringidos aos alunos, tal como exposto pelo aluno 4:
Aluno 4: No I ciclo, alguns professores me mandavam levantar adobos, acarretar água, buscar arreia. Isso me doe bastante porque eu estou a vir da escola, sai da escola às 13 horas para sair mais e acarretar a água, isso também me marcou bastante.

No segundo grupo, considerado de desrespeito às normas tanto de convivência social como as estabelecidas por leis, e também pelos Estatuto e Regulamento interno, é um dos grandes motivos de acontecimentos dos conflitos na escola. As situações debeladas nas entrevistas dos alunos dão conta da falta de aplicação exemplar das medidas regulamentares, o não respeito pelas normas, o uso excessivo de bebidas alcoólicas e estupefacientes, a falta de respeito pelos alunos, a indisciplina e desordem, a falta do sigilo profissional pelos professores, a prática da injustiça dentro da sala de aula, a apreciação diferenciada das mesmas situações pelo mesmo professor e a corrupção ou a aliciação, tal como podemos notar nos dois extratos da entrevista a seguir:

\footnotetext{
Aluno 9: E também lá na escola não temos lei. Um aluno vai à escola, atrasado e quando este aluno comete grande indisciplina na escola, quer dizer, não falam nada. E há professores que dizem: "Por esse problema que já tem na escola, compra-me um cartão de saldo para o problema ficar ultrapassado." [...] Os professores lá gostam muito de dinheiro. Veja só, o colega está cometer dentro da sala de aulas, bebendo o seu whisky e não sei quê, o professor não fala nada. Há professores que dizem que os alunos não têm respeito, são eles próprios os provocadores.
} 
Aluno 4: Os alunos querem que os professores respeitem os alunos como também os alunos lhes respeitam para que não haja conflitos; os conflitos resultantes decorrem do namoro com as alunas.

Do terceiro grupo fazem parte as situações ligadas às medidas disciplinares excessivas. Como sabemos, uma infracção deve corresponder com a sanção que se deve aplicar ou ainda com uma medida atenuante. 0 que em certos casos não acontece, ultrapassando os limites normais de aplicabilidade. Essas medidas ao invés de trazerem a devida correção ao infrator, provocam mais situações de desavenças e ou psicológicas. No relato dos alunos, controlamos os maus tratos infringidos pelos professores aos estudantes, as punições descabidas e a generalização das medidas punitivas dentro de uma turma quando, às vezes, apenas alguns deles são os que cometeram a desordem ou indisciplina.

\begin{abstract}
Aluno 17: E no meu caso tinha um cabelo normal, penso que deveria ir cortar de jeito que aquilo estava, mas o professor veio e raspou-me o cabelo com lâmina e eu não fiquei a gostar e eu implorei ao professor que depois das aulas iria cortar o cabelo. 0 professor não quis entender. E eu disse a ele: Já que é assim, eu não vou mais assistir às aulas. Mas o professor não quis entender. Pegou no livro de ponto e me marcou uma falta vermelha. E cada vez que eu queria assistir à aula desse professor, ele sempre me metia fora.
\end{abstract}

Os alunos se evidenciam no cometimento da indisciplina e da desordem no seio da comunidade escolar. Para além de provocar conflitos com os membros da direção da escola e com os professores, também, e sobretudo, têm vindo a provocar atritos com os colegas da mesma classe ou da mesma escola, como se verifica no caso a seguir:

Aluno 3: Há professores e colegas da escola que cometem a desordem e quando os professores ou os membros da direção reagirem, vão implicar toda a turma: conhecendo os desordeiros, os outros alunos não vão aceitar de ser inclusos naquele grupo. Ao denunciar, pode ter conflitos com os seus colegas.

No quarto grupo, relacionado com questões comportamentais e atitudinais dos docentes e discentes, as situações referenciadas nas entrevistas dos alunos apontam a inveja dos professores em certas amizades dos alunos, a má educação familiar, a nãoaceitação da correção, o mau comportamento, a insinuação, os boatos, as fofocas e as intrigas no seio da comunidade escolar, como geradoras de conflitos tal como indicadas pelos Alunos 9 e 8 .

Aluno 9: A partir daí, eu não gostei de me insinuar nas coisas que não fiz. Começamos a discutir. Já não cheguei de lutar com ele, mas só discutimos. Assim ele levou o problema até a direção da escola e disse que iria repetir 3 anos a $7^{\text {a }}$ classe. Parei de estudar, quando refleti disse que deveria continuar com os meus estudos.

Aluno 8: [...] Esse professor da EMC (Educação Moral e Cívica) não parece que dá essa disciplina. Foi um dia, veio lá na escola e entrou numa das turmas da $8^{\text {a }}$ classe. Estava a conversar com a 
minha irmã e logo chamou a minha irmã de feia e disse: "Feia sai fora! Oh! Feia sai fora!” E a minha irmã disse: "professor se eu sou feia, o professor também é feio." Começaram a discutir lá e o professor começou a ofender a irmã e ela também começou a ofender o professor. E isso não dá porque o professor deve se comportar como professor.

\section{Tipos de conflitos}

Em análise estão os tipos de conflitos na relação professor-aluno que ocorrem na escola do I ciclo de Buco-Zau. Aqui aparecem, às vezes, sob forma de consequências das situações conflituosas ou mesmo dos modus operandi. Por isso, o ódio, o rancor, as ameaças, assim como as agressões físicas e verbais, como no caso referenciado pelo aluno 21, são tipos de conflitos a considerar:

Aluno 21: Agressões verbais, agressões físicas, ameaças, vinganças, etc. [...]

Resumidamente, o conjunto de situações encontradas no palco da realização da nossa investigação pode se reagrupar em quatro itens, que se discriminam como se seguem: o abuso da autoridade professoral, o desrespeito às normas estabelecidas, as medidas disciplinares excessivas aplicadas no exercício da autoridade do professor, e as questões comportamentais e atitudinais manifestadas pelos docentes e discentes.

Assim, reagrupamos na categoria do abuso da autoridade professoral o conjunto de situações em que o professor se apresenta como um dominador para obtenção de favores ou de satisfação a uma necessidade por meios ilícitos, de uma maneira sedutora ou coerciva, sem o consentimento do aluno. Aqui, retomamos o assédio sexual, o namoro entre professor e aluna, a não consideração do trabalho do aluno, o complexo de superioridade dos professores, o não respeito ao horário, os trabalhos caseiros infringidos aos alunos, os problemas evocados fora do contexto.

Aqui destacamos o outro grupo de situações que se prendem com o desrespeito das normas estabelecidas para uma boa convivência social. Em cada sociedade existem as leis e normas que permitem uma harmonia na convivência entre os elementos da comunidade. Se essas normas não forem respeitadas por alguns, desarmoniza-se a convivência, o que conduz aos conflitos entre os respeitantes e os não respeitantes. Nesse grupo de situações, evocamos aqui aquelas que foram citadas pelos próprios alunos na lista que segue: a falta de aplicação regular das medidas regulamentares, o não respeito pelas normas, a bebedeira e uso de drogas, a falta de respeito pelos alunos, a indisciplina e a desordem dos alunos, a falta de sigilo profissional, a injustiça praticada na sala de aula, a apreciação diferenciada das situações.

0 terceiro grupo, caracterizado por medidas disciplinares desmedidas, soma o conjunto de problemas citados atinentes às medidas aplicadas como punições aos alunos fora da infração e de uma maneira brutal e/ou generalizada. Neste campo entram os maus tratos, as punições descabidas e a generalização das medidas punitivas.

0 quarto grupo faz referência às questões que se prendem com o comportamento e atitudes manifestados pelos professores tanto na sala de aulas e no recinto escolar, assim como em outros ambientes públicos, como podemos considerar nas seguintes situações 
citadas: inveja do professor em relação às amizades dos alunos, má educação familiar, não-aceitação da correção, boatos, intrigas, fofocas, insinuação, mau comportamento.

\section{Conclusões e discussão}

Sendo o conflito inevitável dentro de um grupo de indivíduos (THAKORE, 2013) e contrariamente à abordagem atual sobre os conflitos, que defende a manutenção de um nível mínimo dessas situações dentro de uma organização para o desempenho e a manutenção do grupo (ROBBINS, 2002; ROBBINS; JUDGE, 2012), a percepção geral dos alunos é que o conflito tem contornos desastrosos e prejudiciais que "envenenam" as relações humanas capazes de engendrar situações que se complicam cada vez mais na vida de uma organização como a escola. Neste caso, baseiam-se no lado negativo de conflito para determinar que ele é sempre prejudicial nas nossas relações de convivência social. A concepção geral dos alunos corrobora com o pensamento de certos autores que consideram o conflito como uma oposição em ideais, necessidades, crenças ou fins entre indivíduos ou grupos de indivíduos (THAKORE, 2013; GÖKSOY; ARGON, 2016), capaz de produzir efeitos muito negativos. No entanto, demonstram o interesse na resolução dessas situações para não se chegar a consequências nefastas, porque os resultados dos mesmos não são predestinados, o que pode beneficamente ser resolvido e levar à qualidade final do produto em discussão, tal como afirmam alguns autores (ALFA; OBOEGBULEM, 2013; SOCÍAS, BRAGE; TORRELLÓ, 2003; TOMO, 2012). Por isso, considera-se o conflito como não sendo mau ou bom, mas essencial à vida social humana que provê o desenvolvimento das escolas como analisado por Hüssein Yildizoglu e Berrin Burgaz (2014), Fatma Özmen, Cemal Aküzüm e Leyla Aküzüm (2011).

No ambiente escolar e na relação professor-aluno, as diferenças culturais e ou educacionais entre alunos e entre alunos e professores ou entre professores mostram-se propensas à criação de atritos decorrentes da relação na visão dos alunos. Os mesmos apontam a falta de aplicação das normas ético-deontológicas no exercício das suas funções como a causa principal de ocorrências conflituais naquela escola. Isto vai ao encontro do pensamento de Türkan Ozgan (2016) que estatua que para além da falta de comunicação, a dominação ou o espírito de superioridade na relação Professor-Aluno tem causado situações de desavenças entre as partes. De acordo com Marta Lorena Salinas, Diana María Posada e Luz Stella Isaza (2014), as causas internas inerentes à vida da escola não são responsáveis exclusivas da grande carga de situações conflituosas, apontam também alguns fatores externos tais como a pobreza, a marginalidade, as altas taxas de desemprego, a violência intrafamiliar, o modelo da educação, os padrões culturais, etc. Na visão de Türkan Argon (2009), de Soner Dogan (2016) e de Christofer Murray e Kelly M. Murray (2004), existem muitos fatores que afetam a relação professor-aluno e que conduzem aos conflitos tais como as diferenças de atitudes e crenças, a superlotação das turmas, a falta de qualidade no processo do ensino, as incompreensões nos processos de comunicação, os insuficientes recursos pedagógicos, e no caso dos casais, Lauren M. Papp (2018) acrescenta as tarefas e os hábitos. 0 aspecto regulamentar sublinhado pelos alunos 
é também reconhecido como produtor de conflitos (LAMBERT et al., 2017). Muitas dessas causas devem ser inclusas nas características e comportamentos dos professores e alunos.

É assim que, na base da investigação levada a cabo, podemos concluir que, na escola em estudo, a falta de aplicação das medidas ético-deontológicas da parte dos docentes e os casos comportamentais ou de civilidade dão acesso à proliferação de conflitos caracterizados pelas agressões físicas ou verbais, podendo produzir vingança, ódio, rancor, remorso, insinuações, obstinação, arrogância, fatalismo, desprezos, desobediência, insurreições, revoltas, entre outras. As causas determinam a maioria das vezes as situações vividas.

Os conflitos assinalados e mais frequentes apontados por vários autores a nível escolar, tem uma classificação variada (ROBBINS, 2009), mas, e sobretudo, baseada na relação aluno-aluno. Os mais referenciados nesta relação prendem-se com a violência, o bullying, o cyberbullying, a indisciplina na sala de aula (MATOS et al., 2018). Por alguma parte, os mesmos acabam por afetar a relação professor-aluno dado o ambiente em que os dois tipos de elementos se encontram. Na nossa investigação, encontramos as agressões tanto físicas como verbais entre o professor e o aluno ou ainda o bullying que não passa da violência analisada por outros autores a nível escolar.

Embora o aspecto regulamentar seja produtor de conflitos, a via para a prevenção dos mesmos é o reforço da regulamentação na sua concepção e aplicação.

Sabendo que não há nenhuma organização tão perfeita sem conflitos, para reduzir as consequências negativas dos mesmos, ou ainda aproveitar dos aspectos positivos do conflito evoca-se a sua gestão ou a resolução de conflitos (ROBBINS, 2002) como meio de mitigar os seus efeitos nefastos. Variadas formas de resolução são retomadas por Nnior Machomi Morake, Ratau Monobe e Stephonia Dingwe (2011) que consistem na cooperação, competição, compromisso, evitamento ou acomodação. A melhor forma de resolução das situações conflituais é o engajamento ao diálogo direto ou por via de negociação, para apaziguar os espíritos, encontrar consensos e buscar os aspectos positivos que possam dinamizar a organização ou as relações interpessoais. E qualquer modelo que se pretende construir deverá se basear no diálogo participativo e inclusivo. As abordagens participativas e deliberativas nas discussões são métodos utilizados como uma forma de lidar com esses problemas (LUNDEGARDH; WICKMAN, 2007; RUDSBERG; ÖHMAN, 2010).

Para terminar, podemos resumir dizendo que a concepção do conflito pelos alunos (no contexto atual) ficou desajustada, e as causas e situações mais referenciadas relacionamse com a humanização dos serviços da educação em que as agressões tanto físicas como verbais lideram a lista dos conflitos mais frequentes na relação professor-aluno, no que se refere ao contexto do centro educativo em estudo.

\section{Limitações do estudo e investigações futuras}

Sendo um estudo de caso, os resultados obtidos não podem ser generalizados para mais escolas. As conclusões obtidas são particulares, e desta feita abre-se logo uma brecha para a comparação com outras escolas, ou para a continuidade da mesma investigação em algumas 
escolas do I ciclo na região, ou em todo país e outros países, com vistas a generalização dos mesmos. No caso presente, os resultados são também influenciados pelo contexto em que ocorrem os conflitos, assim como as respostas e comentários dos entrevistados.

Em segundo lugar, o número de indivíduos que participaram como uma amostra representativa dos alunos da escola, por ser uma amostra intencional, e em seguida não termos recolhido os dados de todos quanto tiveram conflitos com os professores por não terem aceite de falar conosco, coloca-nos uma certa limitação no estudo que seria mais abrangente e conclusivo. Alguns casos do nosso conhecimento que muito podiam enriquecer esta pesquisa não saíram à tona pelas suspeitas acusações que os alunos não queriam fazer dos seus docentes.

A outra limitação, não menos importante, refere-se à perspectiva dos alunos somente. Dirigimos as nossas atenções nas causas dos docentes consideradas pelos alunos por serem os principais réus acusados de violência e outros tipos de conflitos na escola, sem ter em atenção que mais autores têm vindo a suscitar este fenômeno a nível dos estabelecimentos escolares. No entanto, algumas vozes mais autorizadas podiam auxiliar em compreender o surgimento dessas situações naquele centro de aprendizagem, sendo elementos da comunidade escolar para mais subsídios e compreensão da causa. Neste contexto, é recomendável que noutros estudos do gênero, outras vozes se juntem para termos os pontos de vistas diferentes com uma variada gama dos instrumentos para recolha de mais dados específicos.

No entanto, acreditamos que o nosso estudo fornece resultados significativos para continuar a contribuir na pesquisa sobre os conflitos escolares, para generalização do ponto de vista dos estudantes nas escolas do ensino secundário na região, ou numa amostra do país, a fim de se vislumbrar uma perspectiva de gestão e resolução que conduza aos efeitos positivos, depois do estudo de um modelo adaptativo. Outrossim, sendo as investigações de gênero raras nestas paragens, o estudo das situações conflituais no âmbito da comunidade escolar seria uma valiosa contribuição na compreensão do fenômeno. Fariam também questão de futuras investigações a compreensão do fenômeno através dos diferentes grupos que constituem a comunidade escolar.

\section{Referências}

ABDULKADIROGLU, Atalia; CHE, Yeon-Koo; YASUDA, Yosuka. Resolving conflicting preferences in school choice: "The Boston mechanism" reconsidered. American Economic Review, New York, v. 101, p. 1-14, fev. 2011. Disponível em: http://www.aeaweb.org/articles.php?doi=10.125/aer.101.1.1. Acesso em: 20 set. 2017.

AFFUL-BRONI, Anthony. Conflict management in ghanaian schools: a case study of the role of leadership of Winneba Senior High School. International Journal of Education Planning \& Administration, New Delhi, v. 2, n. 2, p. 65-76, mar. 2012.

ALFA, Idoko Alphonusu; OBOEGBULEM, Angie. Conflict resolution strategies in non-government secondary schools in Benue State, Nigeria. US-China Education Review, New York, v. 3, n. 2, p. 91-102, fev. 2013. 
AMADO, João; FREIRE, Isabel; CARVALHO, Elsa; ANDRÉ, Maria João. 0 lugar da afetividade na relação pedagógica: contributos para a formação de professores. Revista de Ciências da Educação, São Paulo, v. 8, p. 75- 86, jan. 2014.

ANGOLA. Lei de Bases do Sistema Educativo, Lei nº 13/01. Diário da República, Luanda, n. 65, I Série, 31 dez. 2001.

ANGOLA. Lei de bases de educação e ensino nº 17/16. Diário da República, Luanda, n. 179, I série, 07 out. 2016.

ARGON, Türkan. Factor analysis and results in Scale for causes of conflict in the classroom. Theory \& Practice, Sakarya, v. 9, n. 3, p. 1001- 1041, 2009. http://dx.doi.org/10.1007/s10447-007-9033x.

BERRY, Daniel John; O'CONNOR, Erin. Behavioral risk, teacher-child relationships, and social skill development across middle childhood: a child-by-environment analysis of change. Journal of Applied Developmental Psychology, Illinois, v. 31, n. 1, p. 1-14, jan. 2010.

BHUTTA, Zulfiqar A.; YOUSAFZAI, Aisha K.; ZIPURSKY, Alvin. Pediatrics, war, and children. Current Problems in Pediatric and Adolescent Health Care, New York, v. 40, p. 20-35, fev. 2010.

BOURNE, Paul Andrew et al. Strategies in dealing with violence in schools: perceived effectiveness of conflict managements strategies used by education leaders in reducing students'disagreements. Journal of Psychiatry, Minneapolis, v. 18, n. 2, p. 1-11, fev. 2015.

CROSNOE, Robert; JOHNSON, Monica Kirkpatrick; ELDER, Glen H. Intergenerational bonding in school: the behavioral and contextual correlates of student-teacher relationships. Sociology of Education, London, v. 77, p. 60-81, jan. 2004.

DE GUZMAN, María Victoria Pérez; AMADOR MUÑOZ, Luis V.; VARGAS VERGARA, Montserrat. Resolución de conflictos en las aulas: un analisis desde la investigación-acción. Revista Interuniversitária, Sevilha, v. 18, p. 99-114, 2011.

DOGAN, Soner. Conflicts management model in school: a mixed design study. Journal of Education and Learning, Sivas, v. 5, n. 2, p. 200-219, mar. 2016.

DOUCEY, Marie. Understanding the root causes of conflict: why it matters for international crisis management. International Affairs Review, Seattle, v. 20, n. 2, p. 1-11, 2011.

DRUGLI, May Britt; HJEMDAL, Odin. Factor structure of the student relationship scale for Norwegian schoolage children explored with confirmatory factor analysis. Scandinavian Journal of Educational Research, Oslo, v. 57, n. 5, p. 457-466, fev. 2013.

GÖKSOY, Süleyman; ARGON, Türkan. Conflicts at school and their impact on teachers. Journal of Education and Training Studies, Düce, v. 4, n. 4, p. 197-205, abr. 2016. 
HAMRE, Bridget K.; PIANTA, Robert C. Early teacher-child relationships and the trajectory of children's school outcomes through eighth grade. Child Development, Michigan, v. 72, p. 625-638, abr. 2001.

HAMRE, Bridget K.; PIANTA, Robert C. Student-teacher relationships. In: BEAR, G. G.; MINKE, K. M. (ed.). Children's needs III: development, prevention, and intervention. Washington, D. C.: National Association of School Psychologists, 2006. p. 59-72.

HAMRE, Bridget K.; PIANTA, Robert C.; ALLEN, Joseph P. Teachers'perceptions of conflicts with young students: lookin beyond problem behaviors. Social Development, London, v. 17, n. 1, p.115-136, fev. 2008.

HAREL-FISCH, Yossi et al. Psychological outcomes related to subjective threat from armed conflict events (STACE): findings from Israeli-Palestinian cross-cultural HBSC study. Child Abuse and Neglect, Ramat Gan, v. 34, n. 9, p. 623-638, set. 2010. http://dx.doi.org/10.1016/j.chiabu.2009.12.007.

HOJBOTA, Ana Marian et al. The facing conflicts and violence in schools: a proposal for a new occupation: the mediation counsellor. Procedia - Social and Behavioral Sciences, Bled, v. 142, p. 396-402, ago. 2014.

KOOMEN, Helma M. Y. et al. Validating the student-teacher relationship scale: testing factor structure and measurement invariance across child gender and age in a Dutch sample. Journal of School Psychology, Amsterdam, v. 50, n. 2, p. 215-234, abr. 2012.

LAMAS, Karen Cristina Alves; FREITAS, Eduarda Resende; BARBOSA, Altemir José Gonçalves. Bullying e relação professor-aluno: percepções de estudantes do ensino fundamental. Psico, Belo Horizonte, v. 44, n. 2, p. 263-272, jun. 2013.

LAMBERT, Eric G. et al.The relationship of work-family conflict with Job stress among Indian police officers: a reasearch note. Police Practice and Research International Journal, Arizona, v. 18, n. 1, p. 37-48, jan. 2017.

LOPES, Claudivan Sanches. A violência no espaço escolar e a relação professor-aluno. 2001. Dissertação (Mestrado em Educação) - Universidade Estadual de Maringá, Maringá, 2001.

LUNDEGARD, lann; WICKMAN, Per-Olof. Conflicts of interest: an indispensable element of education for sustainable development. Environmental Education Research, London, v. 13, n. 1, p. 1-15, jan. 2007.

MALDONAD0-CARREÑO, Carolina; VOTRUBA-DRZAL, Elizabeth. Teacher-child relationships and the development of academic and behavioral skills during elementary school: a within- and between-child analysis. Child Development, Bogotá, v. 82, p. 601-616, mar. 2011.

MATOS, Armanda P. M. et al. Cyberbullying in portuguese schools: prevalence and characteristics. Journal of School Violence, Philadelphia, v. 17, n. 1, p.123-137, fev. 2018.

MILES, Matthew B.; HUBERMAN, Michael A. Qualitative data analisis. 2. ed. Thousand Oaks: Sage, 1994. 
MORAKE, Nnior Machomi; MONOBE, Ratau; DINGWE, Stephonia. Challenges facing managers in managing conflict in schools in the South and South Central Regions of Botswana. US - China Education Review B, Gaborone, v. 5, p. 695-701, 2011.

MURRAY, Christofer; MURRAY, Kelly M. Child level correlates of teacher-student relationships: an examination of demografics characteristics, academic orientations, and behaviors orientations. Psychol. Schools, Hoboken, v. 41, n. 7, p. 751-762, jul. 2004.

MYERS, Sonia S.; PIANTA, Robert. C. Developmental commentary: individual and contextual influences on student-teacher relationships and children's early problem behaviors. Journal of Clinical Child \& Adolescent Psychology, Philadelphia, v. 37, p. 600-608, jul. 2008.

O'CONNOR, Erin E.; COLLINS, Brian A.; SUPPLEE, Lauren. Behavior problems in late childhood: the roles of early maternal attachment and teacher-child relationship trajectories. Attachment \& Human Development, Philadelphia, v.14, p. 265-288, abr. 2012.

OMISORE, Bernard Oladosu; ABIODUN, Ashimi Rashidat. Organizational conflicts: causes, efects and remedies. International Journal of Academic Research in Economics and Management Sciences, Seattle, v. 3, n. 6, p. 118-137, nov. 2014.

OZGAN, Habib. The usage of domination strategies in conflicts between the teachers and students: a case study. Educational Research and Reviews, Washington, D.C., v. 11, n. 4, p. 146-152, fev. 2016.

ÖZMEN, Fatma; AKÜZÜM, Cemal; AKÜZÜM, Leyla. Yönetici görüslerine gore, okul mensuplarinun okullardakiçatisma sonuçlarina yönelik tavir alislari. Dicle University Journal of Ziya Gokalp Education Faculty, Ziya Gökalp, v. 16, p. 86-100, 2011.

PAPP, Lauren M. Topics of marital conflict in the everyday lives of empty couples and their implications for conflict resolution. Journal of Couple \& Relationship Therapy, Wisconsin, v. 17, n. 1, p. 7-24, abr. 2018.

PATIÑO-SANTOS, Adriana. Reflectivity on stories of conflict among Latin American teenage school girls in a multicultural school in Madrid. Bellaterra Journal of Teaching \& Learning Language \& Literature, Southampton, v. 9, n. 3, p. 9-31, ago-set. 2016.

PIANTA, Robert C.; ALLEN, Joseph P. Building capacity for positive youth development in secondary school classrooms: changing teachers' interactions with students. In: SHINN, M. B.; YOSHIKAWA, H. (ed.). Toward positive youth development: transforming schools and community programs. New York: Oxford University Press, 2008. p. 21-40.

PIANTA, Robert C.; STUHLMAN, Megan W. Conceptualizing risk in relational terms: associations among the quality of child-adult relationships prior to school entry and children's developmental outcomes in first grade. Educational and Child Psychology, Cambridge, v. 21, p. 32-45, 2004.

ROBBINS, Stephen P. Bien diriger son equipe. 2. ed. Paris: Nouveaux Horizons, 2009.

ROBBINS, Stephen P. Comportamento organizacional. São Paulo: Prentice Hall, 2002. 
ROBBINS, Stephen P.; JUDGE, Timothy A. Örgütsel davranis. Ankara: Nobel Yayinlari, 2012. Çeviri Editörü: Inci ERdem.

RUDSBERG, Karin; ÖHMAN, Johan. Pluralism in practice: experiences from Swedish evaluation, school development and research. Environmental Education Reasearch, Uppsala, v. 16, n. 1, p. 95-111, fev. 2010. Disponível em: http://dx.doi.org/10.1080/13504620903504073. Acesso em: 19 set. 2017.

SABOL, Terri J.; PIANTA, Robert C. Recent trends in research on teacher-child relationships. Attachment \& Human Development, London, v. 14, p. 213-231, 2012.

SALINAS, Marta Lorena; POSADA, Diana Maria; ISAZA, Luz Stelle. A propósito del conflicto escolar. Revista Electrónica Interuniversitária de Formación del Profesorado, Antioquia, v. 5, n. 4, p. 1-8, ago. 2014. Disponível em: http://www.aufop.org/publica/reifp/02v5n4.asp. Acesso em: 19 set. 2017.

SALLEH, Mohd J.; ADULPAKDEE, Apitree. Causes of conflict and effective methods to conflict management at islamic secondary schools in Yala, Thailand. International Interdisciplinary Journal of Education, Bloemfontein, v. 1, n. 1, p. 15-22, fev. 2012.

SHAHMOHAMMADI, Mehran. Conflict management among secondary school students. Procedia Social and Behavioral Sciences, Tehran, v. 159, p. 630-635, dez. 2014. http://dx.doi.org/10.1016/j. sbspro.2014.12.438.

SILVER, Rebecca B. et al. Trajectories of classroom externalizing behavior: contributions of child characteristics, family characteristics, and the teacher-child relationship during the school transition. Journal of School Psychology, Amsterdam, v. 43, p. 39-60, nov. 2005.

SOCÍAS, Carmen Orte; BRAGE, Lluís Ballestar; TORELLÓ, Josep Lluís Oliver. Estratégias para la resolución de conflictos. Revista Electrónica Interuniversitária de Formación del Profesorado, Antoquia, v. 6, n. 2, p. 1-5, dez. 2003. Disponível em: http://www.aufop.org/publica/reifp/03v6n2.asp. Acesso em: 20 set. 2017.

TATLAH, ljaz Amhmad; IQBAL, Muhammad Zafar. Role of board of governors and parent teacher associations in district public schools in the context of conflicts and challenges. Management, Lahore, v. 1, n. 1, p. 3540, 2011. http://dx.doi.org/10. 5923/j.mm.20110101.04.

THAKORE, Digvijaysinh. Conflict and conflict management. Journal of Business and Management, Surat, v. 8, n. 6, p. 7-16 abr. 2013. http://dx.doi.org/10.9790/487X-0860716.

TOM0, Rieko. A cultural comparison of conflict-solution styles displayed in the japanese, french, and german school texts. Psychology Research, Kyoto, v. 2, n. 12, p. 719-728, dez. 2012.

TOROS, Karmen. School-based intervention in the context of armed conflict: strengthening teacher capacity to facilitate psychological support and well-being of children. International Journal of Humanities and Social Science, San José, v. 3, n. 7, p. 228-237, nov. 2013. 
VASQUEZ-SALGADO, Yolanda; GREENFIELD, Patricia M.; BURGOS-CIENFUEGOS, Rocio. Exploring homeschool value conflicts: implications for academic achievements and well-being among latino first-generation college students. Journal of Adolescent Research, Virginia Beach, v. 30, n. 3, p. 271-305, jan. 2015. http://dx.doi.org/10.1177/0743558414561297jar.sagepub.com.

VIEIRA, Carlos Magno Naglis. Indigenous children in city schools: conflicts and tensions in school relations. Série-Estudos, Campo Grande, v. 21, n. 42, p. 167-184, ago. 2016. http://dx.doi.org/10.20435/23181982-2016-v.21-n.42(10).

WAGUDE, Janet. Influence of principals'age on conflict management styles in secondary schools in Kisumu County, Kenya. International Journal of Scientific \& Tecnology Research, Raipur, v. 4, n. 5, p. 105-112, maio 2015.

WEBB, Mi-young L.; NEUHARTH-PRITCHETT, Stacey. Examining factorial validity and measurement invariance of the student-teacher relationship scale. Early Childhood Research Quarterly, Amsterdam, v. 26, p. 205-215, abr. 2011. http://dx.doi.org/10.1016/j.ecresq.2010.09.004.

WHITESIDE, Racheal. Peer mediation as viable option for school conflict resolution programs. Undergraduate Journal of Service Learning and Community-Based Research, Fall, v. 5, p. 1-10, fev. 2016.

YILDIZOGLU, Hüssein; BURGAZ, Berrin. Okul yöneticilerinin bes faktör kisilik özellikleriyle çatisma yönetimi stili tercihleri arasindaki iliski. Hacettepe Üniversitesi Egitim Fakültesi Dergisi, Hecettepe, v. 29 , n. 2, p. 29-42, abr. 2014.

YIN, Robert K. Estudo de caso: planejamento e métodos. Porto Alegre: Bookman, 2001.

Recebido em: 05.12.2019

Revisado em: 04.03.2020

Aprovado em: 28.04.2020

Ernesto Barros André doutorou-se em Ciências de educação na Facultad de Ciencias de la Educación de la Universidad de Sevilla, España. 